\title{
Intracranial necrotizing granuloma caused by Cladophialophora bantiana
}

\author{
Sumit Deb, A. K. Khan, B. Debasish, B. Subroto \\ Department of Neurology, N.R.S. Medical College, Kolkata, India
}

The dematiaceous fungi are a group of pigmented hyphal yeasts best known as agents of chronic skin and subcutaneous infections. Extracutaneous disease is exceptional. We report herewith a case of necrotizing granuloma caused by one member of the group, Cladophialophora bantiana. This organism is fully capable of invading the nervous system of apparently immunocompetent hosts and in many cases does so in the absence of demonstrable foci of extraneural infection. It has also been reported to be the most frequently found causative organism in the central nervous system phaeohyphomycosis. C. bantiana has several older names in the literature including Clodosporium trichoides, $C$. bantianum and Xylohypha bantiana. Patients require treatment with a combination of medical and surgical therapy. Rarity of the case and the usefulness of a simple diagnostic method such as smear cytology, which lead us to the diagnosis, is highlighted by the report.

Key words: Cladophialophora bantiana; dematiaceous fungi; intracranial necrotizing granuloma; phaeohyphomycosis.

Phaeohyphomycosis is a term used to describe infections caused by dematiaceous fungi. One member of the group, Cladophialophora bantiana is specifically neurotropic and is responsible for most central nervous system phaeohyphomycosis. Neuroparenchymal lesions caused by it consist of necrotizing granuloma, multifocal in about $50 \%$ of cases and a similar fraction are affected by fungal meningitis. ${ }^{[1]}$ Complete excision of brain lesions may provide better results than partial excision or aspiration, combined with the use of anti-fungal drugs. This case is one of the rarer ones, which has been followed for 18 months after surgery and has shown significant neurological improvement.

\section{Case history}

A 26-year-old woman, a housewife, a city dweller with no

particular interest in gardening not a known diabetic or hypertensive presented to us with a history of episodic intense headache associated with vomiting of 4 month duration and two episodes of generalized tonic-clonic convulsions which was then followed by gradual, progressive weakness of the right half of the body. The patient did not have a history of undergoing organ transplant, intravenous drug or alcohol abuse. She had never been treated with cytotoxic medication or corticosteroids.

On examination, the patient had bilateral papilledema and an upper motor neuron type of facial paresis on the right side and right hemiparesis. The patients routine hematological and biochemical investigations were within normal limits and she was not immunocompromised.

A computed tomographic scan of the head revealed a granulomatous lesion in the left posterior frontal region with florid perilesional edema. At surgery, the lesion was well circumscribed, firm, minimally vascular with a necrotic center [Figure 1]. A total excision of the lesion was performed. A small amount of tissue was sent for smear cytology examination, which showed many fungal bodies both budding yeast like and hyphal forms. Postoperatively the patent was treated with Am-

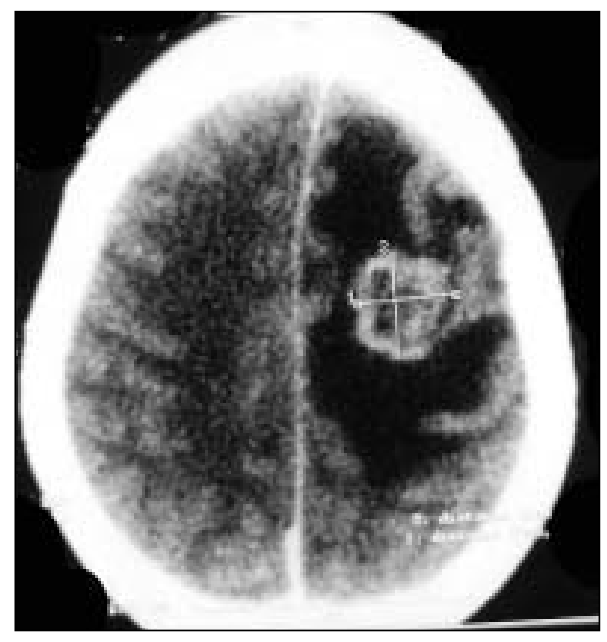

Figure 1: CT Scan showing the granuloma with a hypodense center in the left posterior frontal region with florid perilesional edema

B. 12/1, E.C.T.P. Phase-III, E.M. Byepass, Kasba, Kolkata - 700 107, India, E-mail: sumit_neuro@yahoo.co.in 


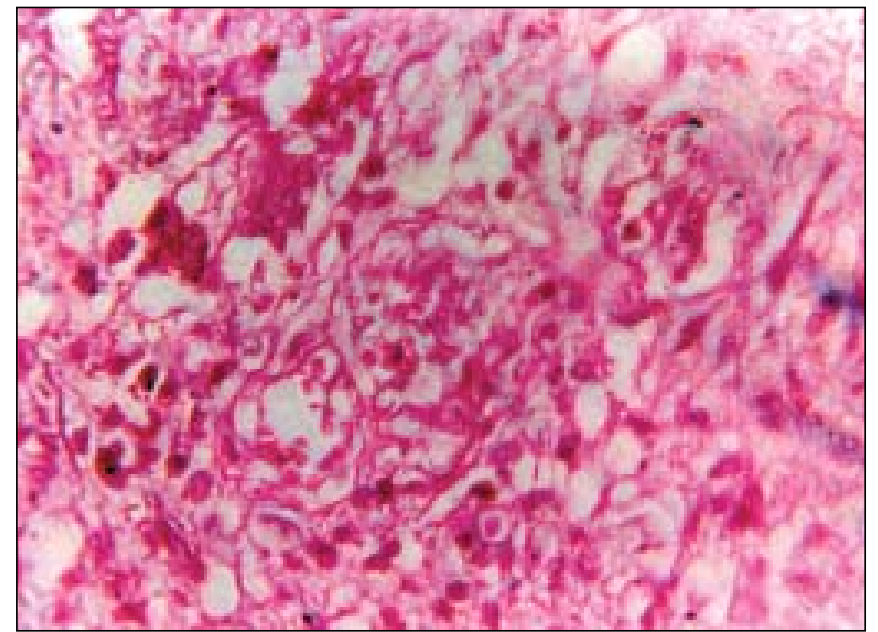

Figure 2: Microphotograph showing both budding yeast like and hyphal form of the fungus (PAS; 270)

photericin B. She had a smooth postoperative recovery and her neurological deficits gradually improved. Consequent upon the availability of smear cytology report a fungal culture was ordered which led to the isolation of $C$. bantiana. The fungal colony appeared jet-black on the reverse and was slow growing, heaped up. Microscopical examination of the mould showed freely branching septate hyphae that gave rise to elliptical dark staining, sparsely branching conidia that grew at $43^{\circ} \mathrm{C}$ and did not liquefy gelatin. section showed histology of brain tissue with an area of necrosis and severe foreign body granulomatous reaction. There were large number of neutrophils in the necrosed area. The granulomatous areas showed many fungal bodies, which showed brown pigmentation. There was also reactive gliosis [Fig. 2]. Our search for any extra neural foci of infection proved futile. Radiological examination of the lungs and paranasal air sinuses was normal. Throat swab, sputum and blood culture did not grow any fungus.

\section{Discussion}

Microscopical examination of tissue obtained at operation, either by the way of smear cytology or frozen section is indeed essential in neurosurgery. Smear cytology is a relatively inexpensive procedure, accurate under trained eyes and could be of immense benefit to neurosurgeons working in a tropical country like ours where intracranial granulomas caused by tuberculosis, fungus or parasites are frequently encountered and are not rare. No signs, symptoms or risk factor of fungal infection were recognizable in our patient. Had the facility for smear cytology examination not been available in our set up and tumor tissue not submitted to it, the causative fungus would have eluded diagnosis. The key to fungal isolation from tissues lies in proper collection of specimen and its transportation to the laboratory in optimal condition without delay. Isolation in culture is required for definite classification. $C$. bantiana is fully capable of invading the nervous system of apparently immunocompetent host and does so in the absence of demonstrable foci of extraneural infection. ${ }^{[2]}$ In a review of 101 cases of primary central nervous system phaeohyphomycosis from 1966 to 2002, C. bantiana accounted for 48 cases and in almost all instances caused brain abscess. ${ }^{[3]}$ An aggressive medical and surgical approach is warranted in treating infection caused by C. bantiana to optimize outcome. We performed a complete excision of the granuloma with the use of Amphotericin B in the postoperative period while others have reported putting their patients on a combination of Amphotericin B and one of the azoles after surgical excision with not so favorable outcome. ${ }^{[3],[4],[5],[6],[7]}$ Our patient has been followed up for 18 months after therapy and has improved neurologically, however she continues to be on anti-epileptic drugs. Only two cases with follow-up period longer than one year are known.

\section{References}

1. Dixon DM, Walsh T.J, Merz WG. Infections due to Xylohypha bantiana (Cladosporium trichoides). Rev Infect Dis 1989;11:515-25.

2. Rosenblum MK, Bilbao JM, Trog LC. Neuromuscular system. In: Rosai J, editor. Ackerman's Surgical Pathology. $8^{\text {th }}$ ed. St Louis: Mosby; 1996;2256

3. Goel A, Satoskar A, Desai AP, Pandya SK. Brain abscess caused by Cladosporuim trichoides. Br J Neurosurg 1992;6:591-3.

4. Gupta SK, Manjunath - Prasad KS, Sharma BS, Khosla VK, Kak VK, Minz $\mathrm{M}$, etal. Brain abscess in renal transplant recipients: report of three cases. Surg Neurol 1997;48:284-7.

5. Nadkarni TD, Goel A, Shenoy A, Karapurkar AP Cladosporium bantianum (trichoides) infection of the brain. J Postgrad Med 1993;39:43-4.

6. Revankar SG, Sutton DA, Rinaldi MG. Primary central nervous system phaeohyphomycosis: a review of 101 cases. Clin Infect Dis 2004;38:206-16.

7. Sood P, Dogra V, Thakur A, Mishra B, Mandal A, Sinha S. Brain abscess due to Xylohypha bantiana. Scand J Infect Dis. 2000;32:708-9 